\begin{tabular}{|c|l|}
\hline Title & Solid Solubility Effect of Metallic Surface Friction \\
\hline Author(s) & Umeda, Kwai; Nakano, Y oshihiro \\
\hline Citation & 北海道大學理學部紀要, 4(1), 70-86 \\
\hline Issue Date & 1951-02 \\
\hline Doc URL & http://hdl.handle.net/2115/34188 \\
\hline Type & bulletin (article) \\
\hline File Information & 4_P70-86.pdf \\
\hline
\end{tabular}

Instructions for use 


\title{
Solid Solubility Effect of Metallic Surface Friction
}

\section{By}

\author{
Kwai UMEDA and Yoshihiro NAKANO
}

(Received March 25, 1950)*

\begin{abstract}
The temperature dependence of the metallic surface friction was studied experimentally for a number of metal pairs by the improved Bownr method. In particular, for metal pairs of limited solubility type the "Solid Solubility Effect" embodied by the formula :

$$
\mu_{0}=\left(\alpha_{t}: \mathrm{ut}_{\mathrm{c}}-\alpha_{\theta}\right) / k
$$

was found. Furthermore, similar phenomena are examined for metal pairs of simple eutectic, continuous solubility, intermetallic compounds, intermediate phase types and solidified mereury as a component. The results seem to be in favour to the local melting theory of Bownis et $a l$.
\end{abstract}

\section{Introduction.}

In 1935, Bownen el al." found the "stick-slip" phenomenon of the friction between a metal ball and a metal plate, and explained it by the so-called "local melting theory" that the stick is caused by the solidification after the momentary melting of the rubbed local surface at the instant when the metal ball begins to slip against the metal plate, and it is the cause of friction forces. We have investigated the temperature effect on friction, expecting that on the supposition of the local melting theory, there should be observed some close relations between the melting characters of metals and the friction, i. e. some influences of the external heating upon the stick-slip.

\section{Experimental Method.}

The experiments were carried out essentially similarly to those

* Presented in part at the annual Tokyo meeting of The Physical Society of Japan, April 29, 1946, at the Takaoka meeting of The Japan Society of Metals, Oetober 16, 1946, and at the Sapporo meeting of the Hokkaido Branch of The Physical Sosiety of Japan, May 1, 1945, and published preliminarily in the Journal of Applied Physics of Japan, 17 (1948) 21 and 25 (in Japanese) and the Physical Review, 75 (1949) 1621. 
of Bowden et al. with only alternation that our spring balance is of horizontally vibrating type while BowDEN's one moves along a vertical arc and results no uniform loading at each position. The load is varied in 10 steps from 0 to $1 \mathrm{~kg}-\mathrm{wt}$ by the compression of another small spring, in contrary to BowDEN's case where the load is only of one value. The linearity relation of friction force versus load is ascertained and its tangent gives the friction coefficient $\mu$ directly. The temperature was varied by small nichrome electric furnace brought under the metal plate to be rubbed, and its surface temperature was measured by means of a Pt-Pt.Rh thermocouple and a $\mathrm{mV}$ meter.

\section{Experimental Results,}

\section{A. Pretiminary Exieriment.}

Preliminarily, fusible metals $\mathrm{Sn}\left(232^{\circ} \mathrm{C}\right)^{*}$ and $\mathrm{Pb}\left(327^{\circ} \mathrm{C}\right)$ were taken, examining the metal pairs Steel-Sn and Steel-Pb, as well as the same metal pairs $\mathrm{Sn}-\mathrm{Sn}$ and $\mathrm{Pb}-\mathrm{Pb}$. In all cases $\mu$ does not change continuously with the temperature $\theta$ but vanishes suddenly at the lower of the melting points of both metals. This was thought at first sight to turn against our expectation.

B. Metal Pans of the Limited Solubiluty Type.

i. $\mathrm{Sn}\left(232^{\circ} \mathrm{C}\right)-\mathrm{Pb}\left(327^{\circ} \mathrm{C}\right)$, Fig. 1.

Expecting the discontinuous change at the melting point observed above for the same metal pairs likely for the different metal pairs, $\mathrm{Sn}-\mathrm{Pb}$ was examined. $\mu$ vanishes, however, at $182^{\circ} \mathrm{C}$, a temperature much lower than either of both melting points, which is just the eutectic temperature of the binary alloy system $\mathrm{Sn}-\mathrm{Pb}$. Magnified figures of the rubbed surfaces of the samples exibit the existence of a liquid state along the rubbed trace on the $\mathrm{Pb}$-plate.

At the first stage, we thought simply that a certain alloy should be formed at the friction boundary by virtue of the so-called local melting and hence $\mu$ should vanish at the eutectic point which can be regarded as the melting point of the alloy corresponding to the true melting point in the case of the same metal pair, and further-

* The temperature bracketted in the rear of the name of metal denotes its melting point in ${ }^{\circ} \mathrm{C}$. 


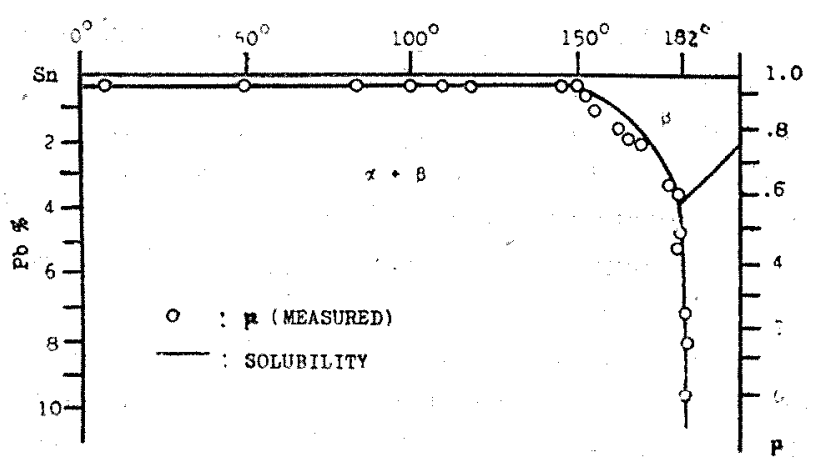

Fig. 1. Friction coefficient is ver'sus temperature $\theta$ plots brought into phase diagram in $\mathrm{Sn}$-side for $\mathrm{Sn-Pb}$.

more this may be the only temperature effect to be observed. Similar phenomena were also observed for the other different metal pairs, too, so that we stated that it could be called "Eutectic Effect" * of metallic surface friction.

At the next stage, when not only the point of $\mu=0$ but also the full course of $\mu$ versus $\theta$ curve ( $\mu$-curve) were determined precisely, it was found that $\mu$ begins to decrease gradually at $146^{\circ} \mathrm{C}$ alleady and vanishes finally at $182^{\circ} \mathrm{C}$ described above. According to HONDA and $\mathrm{ABE}^{(2)}, 182^{\circ} \mathrm{C}$ is a transformation point where $\mathrm{Pb}$ begins to solve much more rapidly into $\mathrm{Sn}$-rich $\beta$-solid solution.

Then, we noticed that there is such a great similarity between the $\mu$-curve and the solid solubility $\alpha$ versus $\theta$ curve $(\alpha$-curve) in the Sn-side that these two curves can be brought into each other with a simple conversion ratio 10 , i. e. 0.1 change of $\mu$ to 0.01 change of solubility of $\mathrm{Pb}$ into $\mathrm{Sn}$. To ascertain the similar phenomena for the other different metal pairs, we examined the following metal pairs of the limited solubility type on referring to JAwnscke's Handbuch der Aller Legierungen ${ }^{(A)}$ and HANses's Aufbau der Zweistofflegierungen ${ }^{(B)}$.

ii. $\operatorname{Sn}\left(232^{\circ} \mathrm{C}\right)-\mathrm{Bi}\left(271^{\circ} \mathrm{C}\right)$, Fig. 2.

, decreases remarkably with temperature rise and vanishes finally at the eutectic point $139^{\circ} \mathrm{C}$, as expected. The $\mu$-curve coincides with the $\alpha$-curve in the Sn-side of the phase-diagram given by Satô and MATsumasmit ${ }^{(3)}$ among many proposed ones of this system,

* This nomenclature was used in the preliminary report presented at the Tokyo meeting of The Physical Society of Japan, April 29, 1946. 


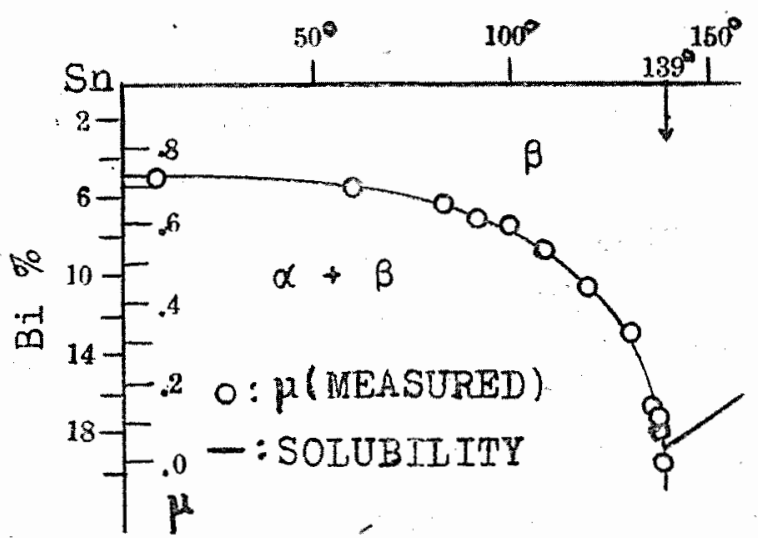

Fig. 2, $\quad \mu-0$ plots brought into phase diagram in Sn-side for Sn-Bi.

assuming 0.1 change of $\mu$ to correspond to 0.02 change of solubility of $\mathrm{Bi}$ into $\mathrm{Sn}$, i. e. conversion ratio 5, in contrary to 10 in the preceding case $\mathrm{Sn}-\mathrm{Pb}$.

iii. $\quad \mathrm{Sn}\left(232^{\circ} \mathrm{C}\right)-\mathrm{Cd}\left(321^{\circ} \mathrm{C}\right)$, Fig. 3.

The $j^{\prime}$-curve shows a kink at about $130^{\circ} \mathrm{C}$ and $\mu$ vanishes at $188^{\circ} \mathrm{C}$. It coincides with the $\alpha-$ curve given by MATsuYama ${ }^{(4)}$ very well with the conversion ratio 10 . According to him, $18 \mathrm{E}^{\circ} \mathrm{C}$ is the eutectic point and $130^{\circ} \mathrm{C}$ is a transformation point of eutectoid.*

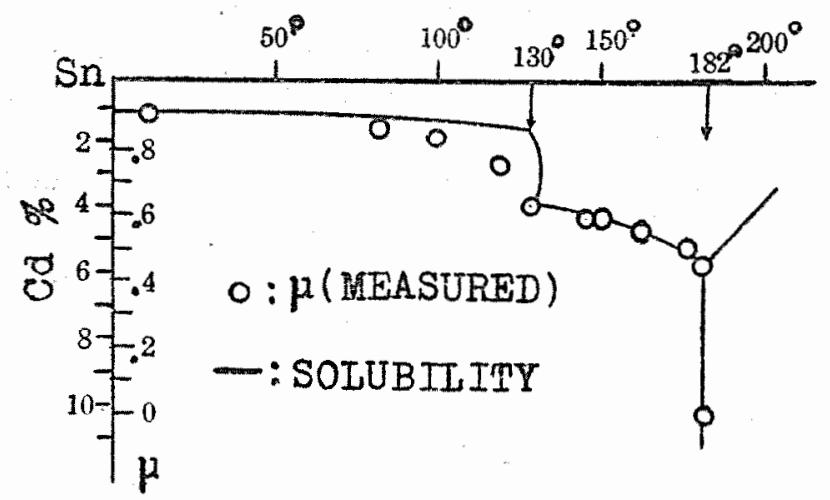

Fig. 3. t $t-0$ plots brought into phase diagram in Sn-side for Sn-Cd.

iv. $\mathrm{Pb}\left(327^{\circ} \mathrm{C}\right)-\mathrm{Sb}\left(630^{\circ} \mathrm{C}\right)$, Fig. 4.

The phase diagrams of this system are slightly different from

* JAENhoK Handbuch gives a smooth solubility curve in the Sn-side and the eutectic point at $177^{\circ} \mathrm{C}$. 


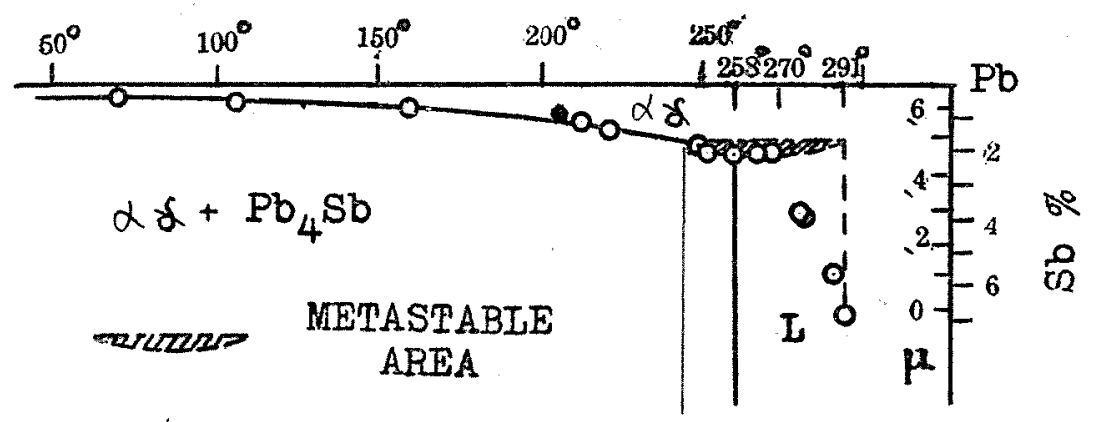

\section{$0: \mu$ (MEASURED) - : SOLUBII ITY}

Fig. 4. $\mu^{-\theta}$ plots brought into phase diagram in $\mathrm{Pb}$-side for $\mathrm{Pb}-\mathrm{Sb}$.

each other among many researchers, among which some state even no solubility in $\mathrm{Pb}$-side. The $\mu$-curve coincides with the conversion ratio 10 to the $\alpha$-curve given by Scrumacuer and Bouron ${ }^{(5)}$ showing a small solubility in the $\mathrm{Pb}$-side by means of thermal analysis. In this case $\mu$ does not vanish at the eutectic point $258^{\circ} \mathrm{C}$ but at $291^{\circ} \mathrm{C}$. This can be explained as follows. In the vicinity of the eutectic point there are two solidus curves almost parallel to the temperature axis (drawn in Fig. 4 by broken and chain lines) which indicate the existence of a sort of metastable state (hatched domain in Fig. 4) so that on passing over the eutectic point and on reaching at the kink point $291^{\circ} \mathrm{C}$ of the chain lined solidus curve they begin to fuse out. On the other hand, the broken lined solidus curve lets well understand the circumstances that the $\mu$-curve begins to fall suddenly at about $270^{\circ} \mathrm{C}$ and the premelting is observed on the rubbed trace at about $278^{\circ} \mathrm{C}$, the kink point of the broken lined solidus curve. Thus the $\mu$-curve gives not only the general feature of the solubility curve but also some informations about the existence of the metastable state as well as such small solubility as undetectable by usual methods.

$$
\text { v. } \mathrm{Bi}\left(271^{\circ} \mathrm{C}\right)-\mathbf{P b}\left(327^{\circ} \mathrm{C}\right) \text {, Fig. } 5 \text {. }
$$

The $\mu$-curve of this system decends at first in a steep inclination and shows at about $80^{\circ} \mathrm{C}$ a sudden kink and then runs along the eutectic line gently and finally ends with $\mu=0$ at the point of solubility limit. The phase diagram of this system is not uniquely determined among researchers. The kink at $80^{\circ} \mathrm{C}$ of our $\mu$-curve corresponds to that of the solubility curve given by Soroson and 


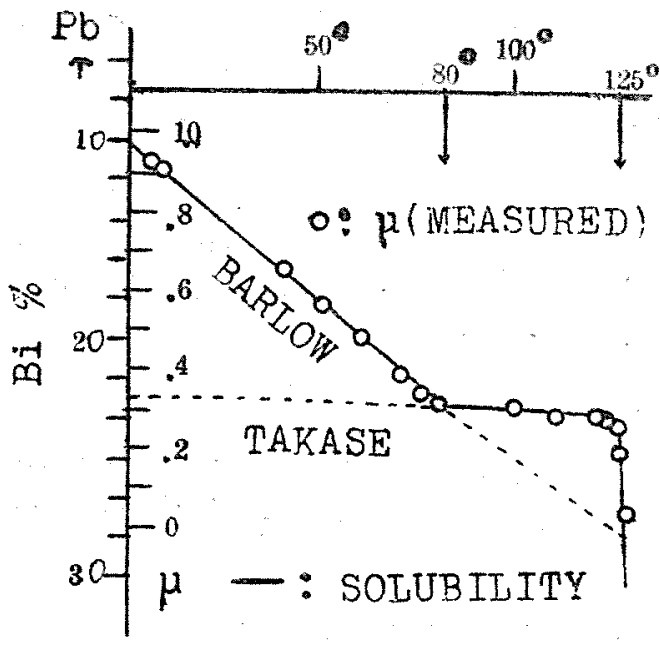

Fig. 5. $\mu-0$ plots brought into phase diagram in $\mathrm{Pb}$-side for $\mathrm{Pb}-\mathrm{Bi}$.

Jon ${ }^{6}{ }^{62} \times$ X-ray-graphically likewise at $80^{\circ} \mathrm{C}$, as well as to the cross point of the solubility curve given by BARrow ${ }^{(7)}$ and that given by TAKAsE ${ }^{(9)}$ each other. Taking $\mu=1$ at $0^{\circ} \mathrm{C}$ (extrapolated) to correspond to $\alpha=0.1$ of $\mathrm{Bi}$ at $0^{\circ} \mathrm{C}$ given by Bariow, and placing the $80^{\circ} \mathrm{C}$ kinks of both curves upon another, the $\mu$-curve coincides with the $\alpha$-curve not in the side of the lower melting point metal $B i$, but in the side of the higher melting point metal $\mathrm{Pb}$, in particular, below $80^{\circ} \mathrm{C}$ with the BArrow's and above $80^{\circ} \mathrm{C}$ with the TAKASE's. $\mu=0$ corresponds to the solubility limit $\alpha=0.3$ at the eutectic point. Consequently, the decrease 1 of $"$ corresponds to the increase 0.2 of $\alpha$, so that the conversion ratio is likely 5 as in the similar case $\mathrm{Sn}-\mathrm{Bi}$ where $\mathrm{Bi}$ is also concerned.

$$
\text { vi. } \mathrm{Cd}\left(321^{\circ} \mathrm{C}\right)-\mathrm{Zn}\left(419^{\circ} \mathrm{C}\right) \text {, Fig. } 6 .
$$

The $\mu$-curve coincides well with the $\alpha$-curve in the side of the lower melting point metal $\mathrm{Cd}$ in the phase-diagram given by $\mathrm{J}_{\mathrm{KN}-}$ Kiss ${ }^{(9)}$ with the conversion ratio 10.

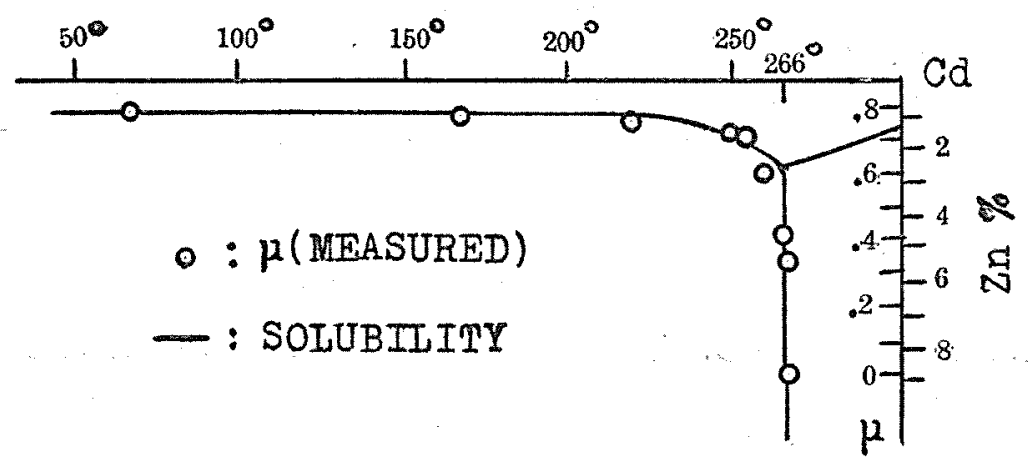

Fig. 6. $x-0$ plots brought into phase diagram in Cd-side for $\mathrm{Cd}-\mathrm{Zn}$.

vii. Summary, TAiste $I$.

As seen from TABtie I, many other metal pairs show likely such 
similar phenomena that $"$ vanishes generally at the eutectic point and the $/$-curve can be brought into the solid solubility curve with an appropriate conversion factor, that is embodied by the formula

$$
\mu_{\theta}=\left(\alpha_{\text {entec }}-\alpha_{0}\right) / k,
$$

where $\alpha_{\theta}$ and $\alpha_{\text {entec }}$ are the solubilities at the temperature $\dot{\theta}$ and the eutectic point respectively, and $k$ is the conversion factor. The formula can be generalized in such a way as

$$
\mu_{\theta}-\mu_{\theta_{0}}=\left(\alpha_{\theta 0}-\alpha_{\theta}\right) / k,
$$

where $\theta_{0}$ is a certain temperature chosen as a standard. Thus we wish to call this phenomenon as "Solid Solubility Effect" of metallic surface friction.

TABre I. Tempera'ure of tanishing friction coefficient and value of fastor $k$ in $E q$. (1) for several me'al

\begin{tabular}{|c|c|c|c|c|c|}
\hline Metal pair & $\begin{array}{c}\text { Lower melt. } \\
\text { pt. }\end{array}$ & $\begin{array}{c}\text { Eutec. } \\
\text { pt. }\end{array}$ & $\begin{array}{l}\text { Temp. } \\
t=0\end{array}$ & $\begin{array}{l}k \text { for } \\
\text { weight } \\
\%\end{array}$ & $\begin{array}{l}k \text { for } \\
\text { atomic } \\
\%\end{array}$ \\
\hline $\mathrm{Sn}-\mathrm{Pb}$ & $232^{\circ} \mathrm{C}$ & $182^{\circ} \mathrm{C}$ & $182^{\circ} \mathrm{C}$ & 10 & 5.9 \\
\hline $\mathrm{Sn}-\mathrm{Bi}$ & 282 & 139 & 139 & 20 & 12 \\
\hline $\mathrm{Sn}-\mathrm{Cd}$ & 282 & 182 & 182 & 10 & 10.4 \\
\hline $\mathrm{Sn}-\mathrm{Zn}$ & 232 & 199 & 199 & 10 & 10 \\
\hline $\mathrm{Sn}-\mathrm{Tl}$ & 283 & 170 & 170 & 10 & 10 \\
\hline $\mathrm{Bi}-\mathrm{Pb}$ & 271 & 125 & 125 & 20 & 20 \\
\hline $\mathrm{Bi}-\mathrm{Cd}$ & 271 & 148 & 148 & $*$ & $*$ \\
\hline $\mathrm{Bi}-\mathrm{Zn}$ & 271 & 254 & 254 & $*$ & $*$ \\
\hline $\mathrm{Tl}-\mathrm{Cd}$ & 302 & 204 & 204 & 10 & 10 \\
\hline $\mathrm{Cd}-\mathrm{Pb}$ & 821 & 247 & 247 & 10 & 10 \\
\hline $\mathrm{Cd}-\mathrm{Zn}$ & 221 & 255 & 255 & 10 & 16.5 \\
\hline $\mathrm{Pb}-\mathrm{Sb}$ & 327 & 258 & $291 \%$ & 10 & 16.5 \\
\hline
\end{tabular}
pairs of limitcd solubility.

* Solubility is too small to determine the value of $k$.

** This coincides with the kink point of the solidus line.

Character 1. The conversion factor $k$ takes the different value according to whether the solubility $\alpha$ is expressed in atomic concentration or in weight one, and in the weight percentage $k$ takes noticeably a constant value 10 for every metal pairs except when $\mathrm{Bi}$ is concerned, while in the atomic percentage it is not the case. (TAbis I)

Character 2. The solubility curve must be taken in the side of the 
lower melting point metal, namely in the side where the atoms of the higher melting point metal dissolve into the lower melting point metal.

Character 3. The only exception is the case where $\mathrm{Bi}$ is concerned. In this case, $k$ has a value 5 and the solubility curve must be taken in the side where Bi dissolve into the other partner metal irrespectively of its melting point. This fact is quite interesting when we recall the statement of HoFe and HANEMANN ${ }^{(10)}$ that the mobility of $\mathrm{Bi}$ in the partner metal lattice is greater than that of the latter in Bi.

Theoretical consideration. The linearity relation between $\mu$ and $\alpha$ can be explained by the fact that the condition for minimum free energy of the rubbed boundary layer determines at each temperature the most stable state giving the solubility of alloys and the maximum friction coefficient $\mu$ which measures the degree of resistance to the mobility of atoms. The value 10 of $k$ may be understood as follows. According to Braue and Barrer (11) the entropy of diffusion of the solute in metallic diffusion process is $\Delta S_{l}=20 \mathrm{cal} / \mathrm{deg}$ per mol at the melting point of the solvent, while the entropy of melting is $\Delta S_{m}=2 \mathrm{cal} / \mathrm{deg}$ per mol, and the ratio of these values gives just the dimensionless numerical value 10. The theoretical consideration along this line is now being studied more precisely.

Exceptional case 1. $\mathrm{Al}-\mathrm{Ag}, \mathrm{Al}-\mathrm{Zn}, \mathrm{Al}-\mathrm{Mg}, \mathrm{Al}-\mathrm{Sn}$.

In these systems, the solid solubility effect is not observed, whereas they are of the type of limited solubility which should change notably with temperature as before. This is due to the oxyde film of a quite high melting point which is so steady as to prevent even the diffusion of small oxygen atom when the coated film has grown up to some extent, so that in our experiment the partner metal atom is forbidden to diffuse as solute any more through the rubbed boundary layer. Therefore, when the amount of the diffused atoms is not so much, the solid solubility effect cannot be seen in the complete form, as it is the case, for example, for some simple eutectic alloy systems.

Exceptional case 2: $\mathrm{Sn}-\mathrm{Tl}, \mathrm{Zn}-\mathrm{Bi}$.

Although $\mu$ vanishes at the eutectic point, $\mu$ has not a definite value corresponding to the small solubility, but rather rises with temperature. This seems to be due to the great stick-slip, but its 
dependences on the relative translation velocity and the proper frequency of the experimental apparatus are being further investigated.

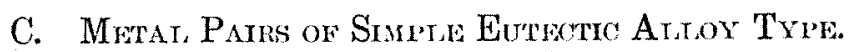

In order to see what rôle the existence of eutectic crystal may play, we examined metal pairs of the so-called simple eutectic type which have no mutual solubility. (TABт, II).

TABre II. Simple eutestic alloy tzp?.

\begin{tabular}{|c|c|c|c|c|c|}
\hline Metal pair & $\mathrm{Sn}-\mathrm{Ag}$ & $\mathrm{Sn}-\mathrm{Al}$ & $\mathrm{Pb}-\mathrm{Ag}$ & $\mathrm{Cd}-\mathrm{Bi}$ & $\mathrm{Sn}-\mathrm{Zn}$ \\
\hline Melting point & $282^{\circ} \quad 960^{\circ}$ & $232^{\circ} \quad 659^{\circ}$ & $327^{\circ} \quad 960^{\circ}$ & $321^{\circ} \quad 271^{\circ}$ & $232^{\circ} \quad 419^{\circ}$ \\
\hline Eutectic point & $2 \$ 1^{\circ}$ & $229^{\circ}$ & $304^{\circ}$ & $146^{\circ}$ & $199^{\circ}$ \\
\hline$\mu=0$ point & $232^{\circ}$ & $289^{\circ}$ & $327^{\circ}$ & $146^{\circ}$ & $199^{\circ}$ \\
\hline
\end{tabular}

These pairs do not show the expected eutectic effect. In the last two cases in TAmIs II, however, if we wait for a sufficiently long time we can see $\mu$ to vanish at the eutectic point. This means that there is slight solubility between them ( 2 to $0.2 \%$ in $\mathrm{Sn}-\mathrm{Zn}$ case $)^{(2)}$ (Fig. 7). The similar effects should be verified in the first three

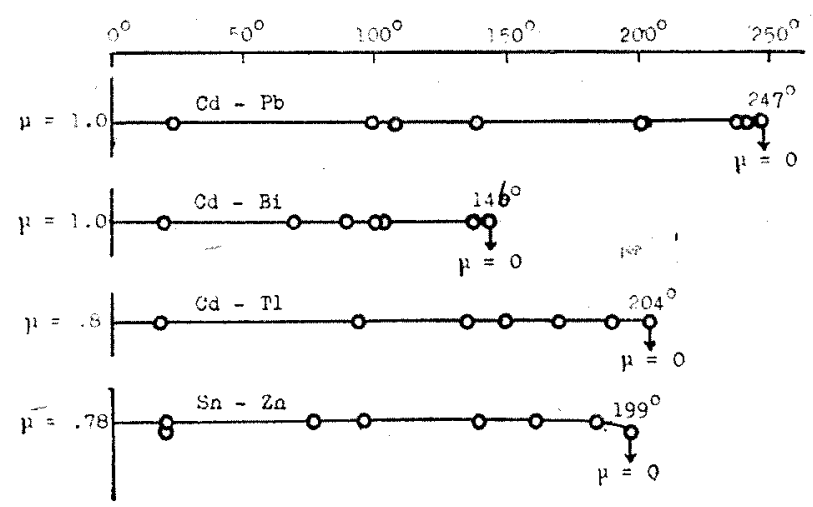

Fig. 7. $\quad \mu-\theta$ plots for $\mathrm{Cd}-\mathrm{Pb}, \mathrm{Cd}-\mathrm{Bi}, \mathrm{Cd}-\mathrm{Tl}$ and $\mathrm{Sn}-\mathrm{Zn}$.

cases, too, but it is very difficult because the eutectic point is near to the melting point of pure metal. From these facts we see that the essential point is not eutectic type of the metal pair but rather mutual solubility between them, so that the terminology of "Solid Solubility Effect" is more appropriate than "Eutectic Effect". 
- D. Metai Pairs of Continuouss Soruminty Type.

The metal pair which is mutually soluble at any ratio, i.e. socalled "lückenlos" soluble, has rather high melting point, so that it is difficult to trace the phenomena up to the melting point. Generally we see, the larger the solubility is, the smaller $\mu$ is. For example, in the case of $\mathrm{Cu}\left(1083^{\circ} \mathrm{C}\right)-\mathrm{Ni}\left(1455^{\circ} \mathrm{C}\right), \mu$ is very small (about 0.56 ) and nearly constant up to the measured temperature $400^{\circ} \mathrm{C}$.

E. Metai Páns of Intermetatim Compounus True.

i. $\operatorname{Mg}\left(651^{\circ} \mathrm{C}\right)-\operatorname{Sn}\left(232^{\circ} \mathrm{C}\right)$, actually $\mathrm{Mg}_{2} \operatorname{Sn}\left(778^{\circ} \mathrm{C}\right)-\mathrm{Sn}\left(232^{\circ} \mathrm{C}\right)$, Fig. 8.

In this system, $\mathrm{Mg}_{\text {. Sn }}$ and pure $\mathrm{Sn}$ form a simple eutectic alloy. The $\mu$-curve is a straight line parallel to the temperature axis as expected by virtue of the vanishing solubility between them. At the eutectic point $\left(200^{\circ} \mathrm{C}\right) \mu$ does not vanish, but rather begins to increase and suddenly falls to zero from the maximum value at the melting point of $\mathrm{Sn}\left(232^{\circ} \mathrm{C}\right)$.

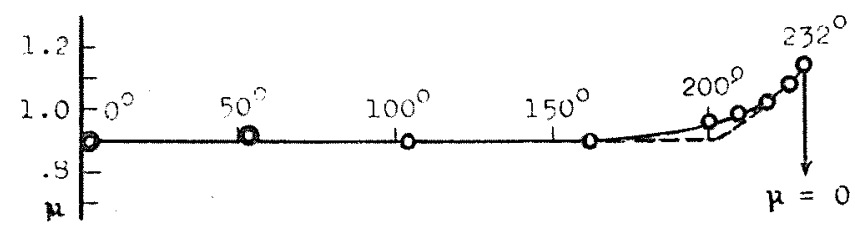

Fig. 8. $\quad \mu-\theta$ plots for $\mathrm{Mg}-\mathrm{Sn}$.

ii. $\mathrm{Mg}\left(651^{\circ} \mathrm{C}\right)-\mathrm{Pb}\left(327^{\circ} \mathrm{C}\right)$, actually $\mathrm{Mg}_{2} \mathrm{~Pb}\left(550^{\circ} \mathrm{C}\right)-\mathrm{Pb}\left(327^{\circ} \mathrm{C}\right)$, Fig. 9 .

In this system, $\mathrm{Mg}_{2} \mathrm{~Pb}$ and pure $\mathrm{Pb}$ have the eutectic point at $250^{\circ} \mathrm{C}$. Corresponding to the existence of some solubility in the $\mathrm{Pb}-$ side, the $\mu$-curve falls linearly with temperature up to $250^{\circ} \mathrm{C}$, and then begins to rise and suddenly falls from the maximum value to zero at the melting point of $\mathrm{Pb}\left(327^{\circ} \mathrm{C}\right)$, similarly to the preceding case $\mathrm{Mg}-\mathrm{Sn}$. In these two systems the eutectic point is certainly a singular point, while there happens no melting.

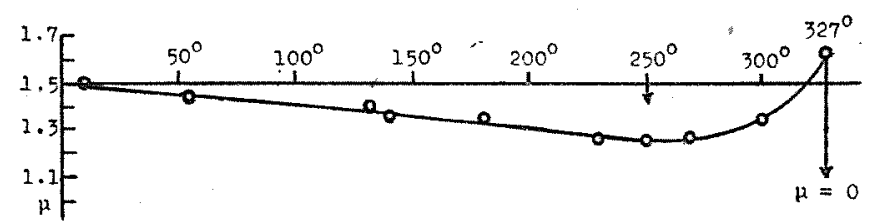

Fig. 9. $\quad \mu-\theta$ plots for $\mathrm{Mg}-\mathrm{Pb}$. 
iii. $\mathrm{Mg}\left(651^{\mathrm{C}}\right)-\mathrm{Zn}\left(419^{\circ} \mathrm{C}\right)$, actually $\mathrm{MgZn}_{5}\left(500^{\circ} \mathrm{C}\right)-\mathrm{Zn}\left(419^{\circ} \mathrm{C}\right)$, Fig. 10 .

In this system, $\mathrm{MgZn}_{.}\left(590^{\circ} \mathrm{C}\right)$ and pure $\mathrm{Zn}$ form a simple eutectic alloy, while the $\mu$-curve runs parallel to the temperature axis similarly to the system Mg-Sn, $\mu$ does not vanish at the eutectic point between $\mathrm{MgZn}_{5}$ and pure $\mathrm{Zn}, 364^{\circ} \mathrm{C}$, but unexpectedly at the peritectic point between $\mathrm{MgZn}_{2}$ and $\mathrm{MgZn}_{5}, 381^{\circ} \mathrm{C}$.

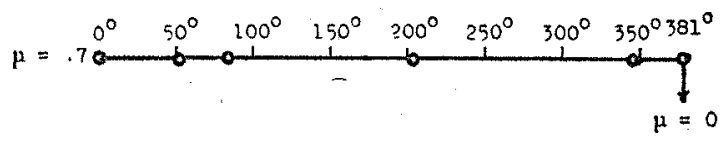

Fig. 10. $\mu-\theta$ plots for $\mathrm{Mg}-\mathrm{Zn}$.

F. Metat Parrs of Intermediate Phase Tyie.

i. $\operatorname{In}\left(156^{\circ} \mathrm{C}\right)-\mathrm{Ag}\left(960^{\circ} \mathrm{C}\right)$, Fig. 11.

JAENECKE and HANSEN state that the eutectic point between $4-$ phase of $\mathrm{In}-\mathrm{Ag}$ and pure $\mathrm{In}$ is $141^{\circ} \mathrm{C}$ and there is no solubility in the In-side. Our $\mu$-curve shows, however, that $\mu$ vanishes at $139^{\circ} \mathrm{C}$. According to Wrinks and EGares ${ }^{3)}$, the solidification temperature varies slightly with the $\mathrm{Ag}$ concentration in In as shown in TABTE III and "eutektikum" is at $2.25 \%$ and $140^{\circ} \mathrm{C}$. Therefore our result implies that the eutectic point is at about $140^{\circ} \mathrm{C}$ and the corresponding solubility is of about $1 \%$. At lower temperatures than $90^{\circ} \mathrm{C}$ there are some fiuctuations of $\mu$ which can be understood from the fact that the lower the temperature is the smaller the solubility is.

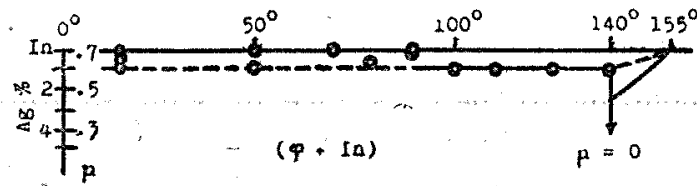

Fig. 11. $\mu^{-0}$ plots brought into phase diagram in In-Side for In-Ag.

TABi,E III. Solidificatisn temp:ralure of $I n-A g$.

\begin{tabular}{l|cccc}
\hline Ag weight $\%$ & 1 & 2 & 3 & 5 \\
\hline Eutectic point & $139^{\circ}$ & $140^{\circ}$ & $140^{\circ}$ & $141^{\circ}$ \\
\hline
\end{tabular}

ii. In $\left(156^{\circ} \mathrm{C}\right)-\mathrm{Cu}\left(1083^{\circ} \mathrm{C}\right)$, Fig. 12.

JAENECKE and HANSEN state that the eutectic point between 4 - 
phase of In-Cu and pure In is $153 \mathrm{C}$. Our $\mu$-curve shows, however, that $\mu$ does not vanish at the eutectic point $153^{\circ} \mathrm{C}$ but at the melting point of In $156^{\circ} \mathrm{C}$, whereas at $153^{\circ} \mathrm{C}$ a tendency of falling is slightly observable. According to W temperature is constant independently of the $\mathrm{Cu}$-concentration in In, as shown in TABLE IV.

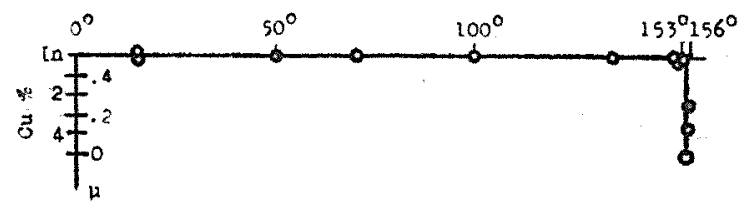

Fig. 12. $\quad \mu-\theta$ plots brought into phase diagram in In-side for In-Cu.

TABI. IV. Solidification temperature of In-Cu.

\begin{tabular}{r|cccc}
\hline Cu weight $\%$ & 1 & 2.22 & 3.3 & $4 . \dot{5}$ \\
\hline Eutectic point & $153^{\circ}$ & $153^{\circ}$ & $153^{\circ}$ & $153^{\circ}$ \\
\hline
\end{tabular}

Hence our result enforces that there is probably no solubility in this case, in contrary to the preceding case In-Ag.

iii. $\mathrm{Pb}-\mathrm{Tl}, \mathrm{Ag}-\mathrm{Zn}, \mathrm{Ag}-\mathrm{Cd}, \mathrm{Cu}-\mathrm{Zn}$, Sn-Sb, Fig. 13, 14, 15, 16.

The phase diagrams of these binary systems are divided complicately into many intermediate phases forming intermetallic compounds. The measured $\mu$-curves have a similarity to their phase boundary curves. By virtue of the non-existence of the eutectic point, $\mu$ vanishes rather at the lower of the melting points of the component metals.

In particular, in the $\mathrm{Cu}-\mathrm{Zn}$ case (Fig. 16), $\mu$ has at lower temperatures two different values, according as whether the rubbing ball is of $\mathrm{Zn}$ or of $\mathrm{Cu}$, but these two curves converge with rising temper-

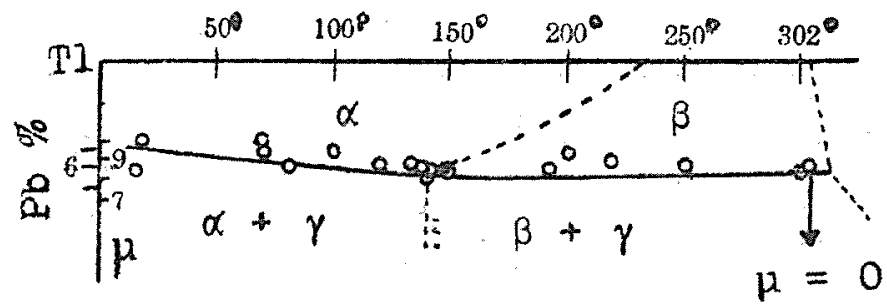

Fig. 13. $\mu 0$ plots brought into phase diagram in Tl-side for $\mathrm{Pb}-\mathrm{TI}$. 


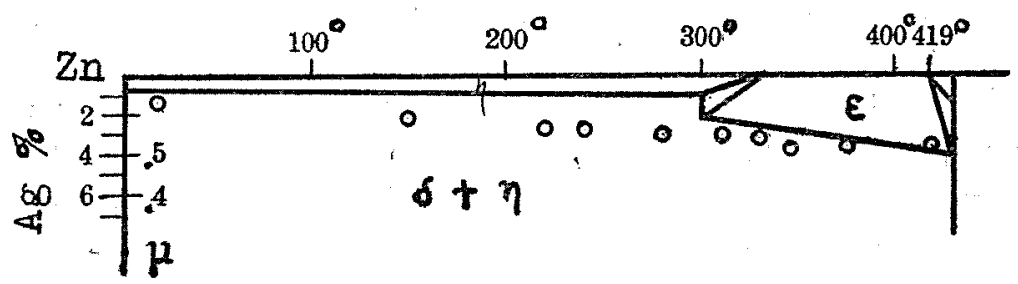

Fig. 14. $t^{-0}$ plots brought into phase diagram in $\mathrm{Zn}$-side for $\mathrm{Ag}-\mathrm{Zn}$.

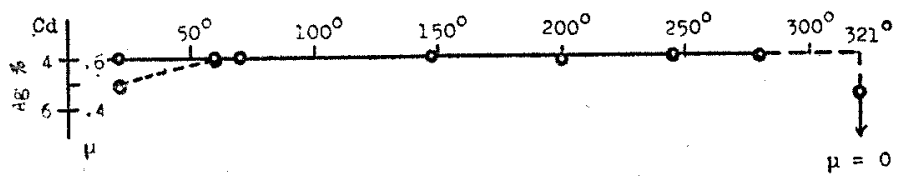

Fig. 15. ${ }^{-1}, \theta$ plots brought into phase diagram in $\mathrm{Cd}$-side for $\mathrm{Ag}-\mathrm{Cd}$.

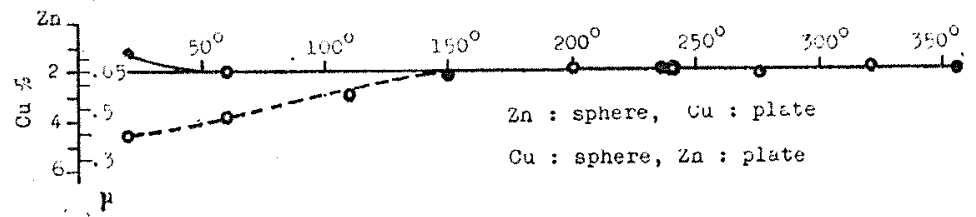

Fig. 16. $\mu-\theta$ plots brought into phase diagram in $\mathrm{Zn}$-side for $\mathrm{Cu}-\mathrm{Zn}$.

atures into one line. This may be ascribed to the fact that the contact of the rubbed surface does not occur exactly in one point.

Generally, for the intermetallic compound type, we cannot state decisively a quantitative relation between $\mu$ and solubility.

iv. $\mathrm{SnSb}\left(\beta^{\prime}\right.$ phase, stable up to $\left.325^{\circ} \mathrm{C}\right)-\mathrm{Sn}\left(232^{\circ} \mathrm{C}\right)$, Fig. 17.

If there are many intermediate phases it is not simply clear, which of those phase boundaries corresponds really to the $\mu$-curve. In order to avoid this ambiguity, we formed really $\beta^{\prime}$-phase of $\mathbf{S n}-\mathrm{Sb}$ and measured $\mu$ between that and pure Sn. The results are similar to the simple $\mathrm{Sn}-\mathrm{Sb}$ case described above, clarifying the behavior more precisely. According to IWAsE ${ }^{(16)}$, the boundary between the

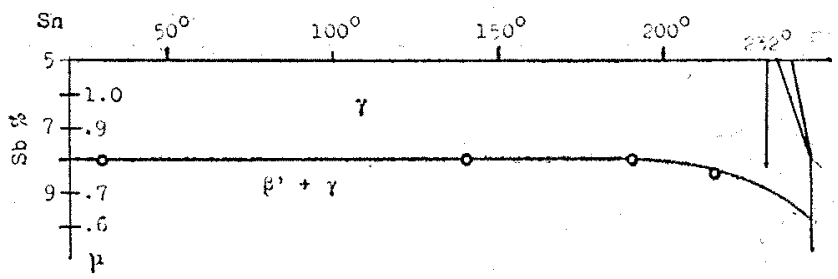

Fig. 17. $t_{-0}$ plots brought into phase diagram in Sn-side for Sn-Sb. 
$\gamma$-phase and the $\beta^{\prime}+\gamma$-phase in the $\mathrm{Sn}$-side is parallel to the temperature axis up to $200^{\circ} \mathrm{C}$ and then in the vicinity of $225^{\circ} \mathrm{C}$ the solubility increases a little in favour,to our result that $\mu$ decreases a little there.

G. Metat. Pains with Solnimede Meroury as thm One Component.

The solid solubility effect of the metallic surface friction described above can be markedly promoted only by active diffusion of the component metal atoms through the contact. Since the diffusion velocity is strongly reduced at lower temperatures, we have examined the effect by means of the metal pairs with solidified mercury as the one component. On blowing liquid air gently all over the free surface of mercury, we had solidified it in a wooden dish and then plane its surface quickly. The surface temperatures are measured by means of a $\mathrm{Cu}$-Constantan thermocouple and a $\mathrm{mV}$-meter.

i. $\mathrm{Hg}\left(-39^{\circ} \mathrm{C}\right)-\mathrm{Tl}\left(303^{\circ} \mathrm{C}\right)$, Fig. 18.

$\mu$ is constant up to $-59^{\prime} \mathrm{C}$ where the $\mu-$ curve begins to decrease up to the melting point of $\mathrm{Hg},-39 \mathrm{C}$. According to JAENECKE and Hansen this temperature $-59^{\circ} \mathrm{C}$ is the eutectic point between the $r$ phase of $\mathrm{Hg}-\mathrm{Tl}$ and the pure $\mathrm{Hg}$. Our result enforces the singularity of $-59^{\circ} \mathrm{C}$ and the existence of a slight solubility (perhaps below $1 \%$ ), although it is not yet given in the literatures.

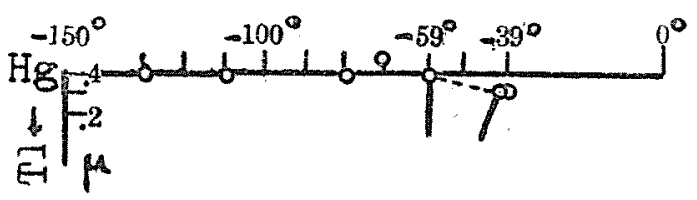

Fig. 18. $\mu-\theta$ plots brought into phase diagram in Hg-side for $\mathrm{Hg}$-Tl.

ii. $\mathrm{Hg}\left(-39^{\circ} \mathrm{C}\right)-\mathbf{R b}\left(39^{\circ} \mathrm{C}\right)$, Fig. 19.

$\mu$ is constant up to $-46^{\circ} \mathrm{C}$ where the $\mu$-curve begins to decrease up to the melting point of $\mathrm{Hg},-39^{\circ} \mathrm{C}$. According to $\mathrm{J}_{\text {AENECKE }}$ and Hansen this point $-46^{\circ} \mathrm{C}$ is a eutectic point between a phase of $\mathrm{Hg}-\mathrm{Rb}$ and pure $\mathrm{Hg}$. Our result enforces the singularity of $-46^{\circ} \mathrm{C}$ and the existence of the slight solubility as like to the preceding case. 


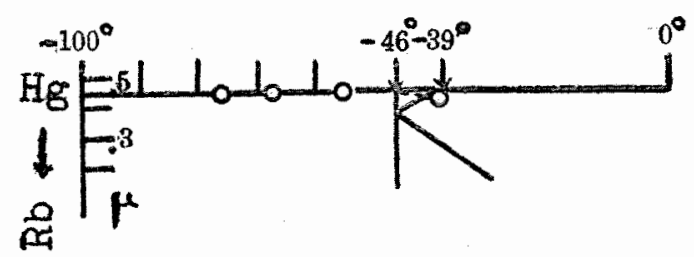

Fig. 19. $\mu-\theta$ plots brought into phase diagram in $\mathrm{Hg}$-side for $\mathrm{Hg}-\mathrm{Rb}$.

iii. $\mathrm{Hg}\left(-39^{\circ} \mathrm{C}\right)-\mathrm{Te}\left(452^{\circ} \mathrm{C}\right)$, Fig. 20.

$\mu$ is constant up to the melting point of $\mathrm{Hg},-39^{\circ} \mathrm{C}$. We found no singular point on the $\mu$-curve. The solubility diagram in the $\mathrm{Hg}-$ side is not yet known while Perminu ${ }^{(17)}$ gives only the Te-side. From our $\mu$-measurement we suppose no eutectic point to exist in the $\mathrm{Hg}$-side in favour to the expected diagram given in HANsEN's book (the broken line in $\mathrm{Abb}$. 322).

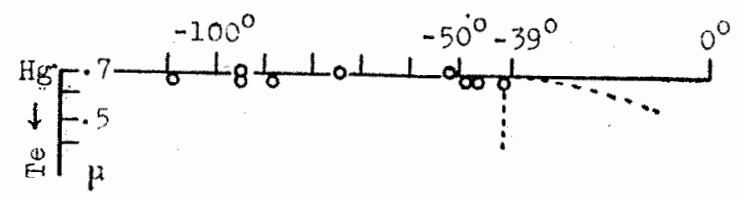

Fig. 20. $\quad t^{-0}$ plots brought into phase diagram in $\mathrm{Hg}$-side for $\mathrm{Hg}$-Te.

From these experiments we see that there exist some diffusion velocity even at much lower temperatures than the melting point of $\mathrm{Hg}$, resulting the solid solubility effect and suggesting the existence of the slight solubility or the exact form of the phase diagram.

\section{Conclusion.}

We have found some characteristic relations between friction coefficient $\mu$ and temperature $\theta$ for many different metal pairs, in particular, for metal pairs of limited solubility type the "Solid Solubility Effect" embodied by the formula:

$$
\mu_{\theta}=\left(\alpha_{\text {entec }}-\alpha_{\theta}\right) / k \text {. }
$$

Furthermore, similar phenomena are examined for metal pairs of simple eutectic, continuous solubility, intermetallic compounds and intermediate phase types. These phenomena can be reversely used to check the phase diagram or to construct it. 
All experiments described above seem to be in favour to the local melting theory of BowDrN et al.

\section{Acknowledgment.}

This work is a part of the researches of the 11th group of the 1st division of The National Research Council of Japan, helped by a grant given by The Ministry of Education.

We wish to express our cordial thanks to late Prof. U. YoshidA in Kyoto University and Prof. T. Fusrwara in Hiroshima University for their interest in this work as the head of the group, and Prof. Y. Ineda, Prof. J. Furuich and Mr. A. Odasenima in Department of Physics, Faculty of Science and Prof. S. KodA in Department of Metallurgy, Faculty of Technology, Hokkaidô University for their kind helps to this work in respect to apparatus and specimens, and further to Prof. U. NAKAYA for his excitation of our interest to Bowden's paper at the colloquium.

$$
\text { References. }
$$

(A) E. Jammoke: Kurzgefasstes Handbuch Aller Legierungen, Leipzig, 1937.

(B) M. HANSEN : Der Aufbun der Zaweistoflegierungen, Berlin, 1936.

(1) F. P. Bowdun: Proc. Roy. Soc. London, A, 169 (1939), 371.

(2) K. Honda and H. ABE: Sci. Rep. Tjhoku Univ., Japan, 19 (1930), 315.

(3) T. SAтô and T. Matsuinsin: J. of Japan Soc. of Metals, 2 (1938), 596, (in Japanese).

(4) Y. Matsuyama: Sci. Rep. Tóhoku Univ., Japan, 20 (1931), 674.

(5) E. E. Scrumacuer and G. M. Bouton: J. Amer. Chem. Soc, 49 II (1927), 167.

(6) D. Soromon and W. M. Jonfs: Phit. Mag., 11 (1981), 1090.

(7) W. E. BARtow: Z. anorg. allg. Chem., 70 (1911), 183. W. Hrron: Z. anorg. allg. Chem., 112 (1920), 131.

(8) T. Takase: J. of Japan Inst. of Metals, 1 (1937), 143, (in Japanese).

(9) C. H. M. Jenknns: J. Inst. of Metals, 36 (1926), 63.

(10) H. V. Hore and H. Hanemañ : Z. Metallieunde, 32 (1940), 112.

(11) R. M. Barmin: Proc. Phys. Soc., 52 (1940), 58.

(12) $2 \%$ : C. T. Hr.rook and F. H. Nivir.te: J. Chem. Soe. London, 72 (1897), 383. 0.2\%: E. JENiKra and L. Roth : Z. Metallkunde, 30 (1938), 143.

(13) F. Whibke and H. EGGirs: Z. anorg. allg. Chem., 222 (1935), 145.

(14) F. Weiré and H. Egcrirs: Z. anorg. allg. Chem., 222 (1935), 273. 
(15) E. A. Owes and I. G. Enmunds: J. Inst. Metals London, 57 (1935), 297.

(16) K. Iwase: Sci. Rep. Tôhotu Univ., Japan, 20 (1931), 358.

(17) G. Primint and C. Aurergir : Gazz. Chim. Ital., 40 II (1910), 46.

Department of Physics, Faculy of Seience, Holkaidô Uniwersity. 